brain and immersed unloaded in sea water in a Petri dish. The brain is stimulated by slight pressure with a forceps. The muscles contract and relax actively again. In more than 20 muscles, the relaxation was from 100 to 200 per cent of their length during the contracted state. If sodium cyanide $(1$ in 10,000$)$ is added to the sea water, the muscles contract, but do not relax actively. Microscopic examination shows that the muscle consists of longitudinal bundles of fibres ${ }^{10}$.

Physiological Laboratory

SUNITA INDERJIT SINGH INDERJIT SINGH

Medical College, Agra. June 14.

${ }^{2}$ Singh, S. I., and Singh, I., Curr. Sei., 19, 60 (1950).

${ }^{2}$ Singh, S. I., and Singh, I., Proc. Ind. Acad. Sci. (in the press).

'Singh, S. I., and Singh, I., Curr. Sci., 20, 48 (1951).

‘ Singh, I., J. Physiol., 96, 367 (1939).

${ }^{5}$ Singh, S. I., and Singh, I., Proc. Ind. Acad. Sci., 31, 351 (1950).

- Singh, I., J. Physiol., 88, 155 (1940).

'Singh, I., Ind. J. Med. Res., 30, 629 (1942).

- Singh, S. I., and Singh, I., Proc. Ind. Acad. Sci., 32, 12 (1950).

- Singh, S. I., and Singh, T., Proc. Ind. Acad. Sci., 30, 270 (1949).

${ }^{10}$ Andrews, E, A., "Studies Biol, Lab., Johns Hopkins Univ.," 4, 389 $(\mathbf{1 8 9 0 )}$.

\section{Diffusion Respiration in Man}

Draper and Whitehead and their co-workers 1 have described a phenomenon which they have called 'diffusion respiration'. In experiments with dogs, they have shown that the blood under certain conditions will be normally oxygenated from the lungs without respiratory movements and without rhythm. ical changes of pressure in the lungs. They explain this phenomenon as follows. Owing to the affinity of oxygen for hæmoglobin, the amount of oxygen removed from the alveoli during apnea exceeds the amount of carbon dioxide that simultaneously enters from the blood. The pressure within the alveoli is therefore reduced below that of the atmosphere, and a continuous inward movement of the dead-space air and the external atmosphere takes place. Essential conditions, however, for diffusion respiration are a high percentage of oxygen in the lungs and in the dead space, $a$ free airway and an adequate circulation. During the first thirty minutes of diffusion respiration the uptake of oxygen is not reduced. After this time the oxygen consumption and the oxygen content of the blood decrease due, probably, to the Bohr effect produced by retention of carbon dioxide, with respiratory acidosis and low blood $p H$.

Investigations of the phenomenon of diffusion respiration in man have not so far been reported. Some practical observations, however, particularly from work on anæsthetics, afford ground for believing that, under the above-mentioned conditions, in man also enough oxygen can be absorbed in the lungs without respiratory movements. We have therefore studied this question.

Method. During intravenous anæsthesia with 'Narkotal' (a short-acting barbiturate), an air-tight tracheal tube with inflatable cuff was passed. After $10 \mathrm{~min}$. inhalation of 100 per cent oxygen from an anæsthetic machine, the tracheal tube was connected with the expiratory hose of a Krogh's spirometer containing pure oxygen. The absence of measurable positive pressure in the spirometer was thoroughly controlled. The respiratory movements and the oxygen uptake were recorded during about five minutes. After that the subjects were given curare and 'narkotal' in adequate doses for apnea. The
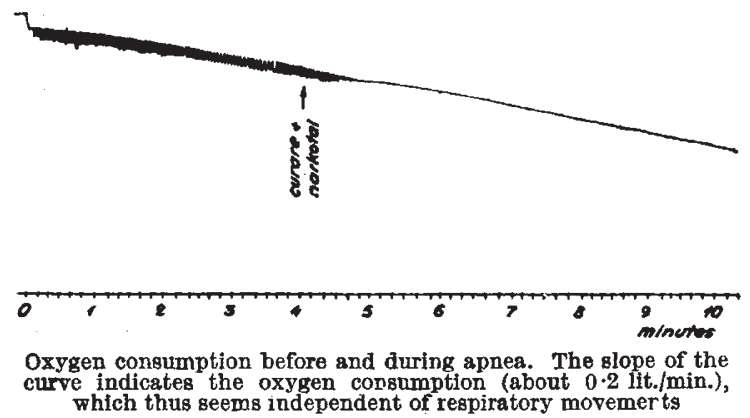

periods of apnea were interrupted by re-connecting the tracheal tube to the anæsthetic machine and starting artificial respiration by rhythmic manual compressions of the re-breathing bag. Immediately before, at the end of, and $5 \mathrm{~min}$. after each period of apnea, samples were taken from arterial blood and from lung air $(7-11 \mathrm{~cm}$. below the tracheal bifurca. tion) for analysis of the oxygen and carbon dioxide content. Pulse-rate, blood pressure and electrocardiogram were recorded during the experiments.

Results. The subjects were kept in apnea for about five minutes, the maximum being $7 \mathrm{~min}$. $20 \mathrm{sec}$. The oxygen consumption during this time was, as a rule, the same as during the period before the apnea. The oxygen content of the blood did not decrease during the apnea. The carbon dioxide content of the blood and of the lung air, on the other hand, increased during the apnea, but after five minutes of artificial respiration with the aid of the anæsthetic machine the values of the carbon dioxide were normal again. No changes of importance were noticed concerning pulse-rate, blood pressure and electrocardiogram. The subjects remained all the time in a very good condition.

Conclusion. The phenomenon of diffusion respiration, which Draper and Whitehead and their coworkers have demonstrated in animals, seems to occur also in man. Accordingly, it is possible to get sufficient oxygen uptake during short periods of time without either spontaneous or artificial respiratory movements and without rhythmic changes of pressure in the lungs, if the circulation is adequate, and if pure oxygen is supplied through a free airpassage. The accumulation of carbon dioxide prevents prolongation of the apnea for a considerable time.

A complete report of these investigations will be published elsewhere.

H. ENGHOFE

M. H:SON HolmdahL

L. Rishorim

Surgical Clinic and Institute of Physiology,

University of Uppsala. June 21.

${ }^{2}$ Draper, W. B., and whitehead, R. W., Curr. Res. Anesthes. Analoes., 28, 307 (1949).

\section{Fluorometric Determination of Natural Estrogens in Urine; Elimination of Fluorogenic Compounds}

THE fluorometric analysis of cestrogens in urine using phosphoric acid for the development of the fluorescence has already been described ${ }^{1,2}$. A difficulty was observed in applying this method to urines in which the cestrogen titre was low, for example, to non-pregnancy urines, since the values obtained with the fluorometric method for normal male and female urines were higher than those yielded by the bioassay (Allen-Doisy test). In addition, a 'quench- 